\title{
DEBATES
}

\section{Acceso a la información pública en América Latina: Análisis de su diseño institucional en Chile, Colombia y México (2002-2014)}

\author{
Access to public information in Latin America: Analysis of \\ institutional design in Chile, Colombia and Mexico (2002-2014)
}

\section{Alfredo Edmundo Fernández de Lara Gaitán}

\section{Resumen}

Este trabajo examina las leyes de información vigentes en México, Chile y Colombia, y las contrasta con un modelo normativo ideal basado en algunas recomendaciones de la Ley Modelo de la OEA. El análisis compara los diseños institucionales a partir de cinco dimensiones: 1) características del régimen de acceso a la información; 2) los sujetos obligados; 3) régimen restringido de excepciones; 4) garantía del derecho o vía judicial; y 5) organismo garante del derecho. La tesis es que el derecho a la información presenta mayor garantía para su ejercicio cuando se contempla la existencia de una legislación específica, que incorpore principios fundamentales del régimen de acceso a la información, combinada con la existencia de un organismo específico (con autonomía presupuestaria, operativa y de decisión), encargado de promover y garantizar dicho derecho, lo cual, genera incentivos para una mayor utilización de los usuarios y una mayor garantía del derecho en caso de denegación.

\section{Palabras clave}

Derecho a la Información Pública; Diseño Institucional; Transparencia; México; Chile; Colombia.

\begin{abstract}
This research examines information laws in Mexico, Chile and Colombia, and contrasts them with an ideal regulatory model based on some recommendations of the OAS Model Law. The analysis focuses on the comparison of the institutional designs from five dimensions: 1) characteristics of the system of access to information; 2) the obligors; 3) restricted regime of exceptions; 4) guarantee of the right or judicial; and 5) institutional body guarantor of the law. The thesis is that the right to information has greater assurance for exercise when the existence of specific legislation, to incorporate fundamental principles of the regime of access to information, combined with the existence of a specific body (with budgetary, operational and decision-making autonomy), in charge of promoting and guaranteeing that right, which generates incentives for broader use by users and a greater guarantee of the right in case of refusal.
\end{abstract}

\section{Keywords}

Right to Information; Institutional Design; Transparency; Mexico; Chile; Colombia. 


\section{Introducción}

El derecho de acceso a la información pública (DAIP) guarda una relación de enorme importancia con el desarrollo democrático de una sociedad, pues es una precondición para el ejercicio de otros derechos políticos, económicos y sociales. También es una herramienta que genera incentivos para el ejercicio de una ciudadanía de mayor intensidad, a la vez que permite una mayor visibilidad y control sobre la función pública por parte de la sociedad. En cuanto a su relación con las políticas públicas, el derecho de acceso a la información se presenta como un requisito indispensable para que el ciclo de políticas se desarrolle de manera transparente, responsable y permita establecer condiciones para la rendición de cuentas vertical y horizontal.

Hay un consenso general entre quienes estudian el desarrollo normativo e institucional que ha tenido el derecho de acceso a la información pública (OEA, 2008; MENDEL, 2009), respecto a la importancia que tiene la existencia de una legislación en la materia que esté acompañada de un organismo público encargado de la supervisión y cumplimiento de este derecho, a fin de obtener mejores resultados en la garantía del régimen de acceso a la información ${ }^{1}$. Precisamente, en esta investigación se busca demostrar, primero analizando el diseño normativo institucional, y luego indagando sobre el uso que las personas han hecho del DAIP en cada una de las unidades de análisis, si lo anterior se puede corroborar en experiencias específicas, de ahí que dos de los casos seleccionados (México y Chile) cuenten con legislaciones y organismos autónomos encargados de garantizar y promover el derecho de acceso a la información pública ${ }^{2}$, en tanto, la tercera unidad de análisis (Colombia), aunque tiene la legislación más reciente, carece de un organismo de supervisión autónomo.

El objetivo es analizar, de manera detallada, la calidad normativa de las legislaciones en materia de DAIP de México, Chile y Colombia. Asimismo, se busca encontrar las similitudes y diferencias existentes entre los estudios de caso, a partir de la comparación de éstos con un tipo ideal basado en la Ley Modelo Interamericana

\footnotetext{
1 "Los Estados deberían establecer mecanismos independientes de cumplimiento, como las Comisiones de Información, que constituyan vehículos de apelación asequibles, de bajo costo, y oportunos. En la medida en que sea necesario, dichas agencias deberían tener el poder de tomar decisiones vinculantes y ordenar la divulgación de la información”. Véase, OEA (2010a).

${ }^{2}$ Para mayor detalle véase Guillán (2013).
} 
sobre Acceso a la Información Pública de la Organización de Estados Americanos (OEA), una legislación que fue realizada por grupo de expertos en la materia ${ }^{3}$.

A partir de este tipo ideal se han tomado cinco dimensiones que se consideran sustanciales para un conocimiento mínimo de un régimen de acceso a la información: 1) características del régimen de DAIP; 2) sujetos obligados; 3) régimen restringido de excepciones; 4) garantía del régimen: apelaciones y vía judicial; y 5) existencia de un organismo de información garante del derecho.

Las preguntas de investigación a partir de las cuales se desarrolló este trabajo buscan responder las siguientes cuestiones: ¿Cuál es la calidad normativa institucional del régimen de acceso a la información en México, Chile y Colombia? ¿Cuáles son las similitudes y diferencias existentes entre el diseño institucional del régimen de acceso a la información de México, Chile y Colombia? ¿Qué resultados similares o diferentes se han obtenido en el uso del sistema de acceso a la información pública por parte de las personas que ejercen este derecho en México, Chile y Colombia?

La hipótesis es que el derecho de acceso a la información, el cual se ha implementado en América Latina mediante diversos modelos, ha mostrado mejores resultados para su ejercicio cuando el diseño institucional relacionado con este derecho contempla la existencia de una legislación específica, en la que se incorporen los principios fundamentales del régimen de acceso a la información, así como la existencia de un organismo específicamente encargado del control e implementación con autonomía presupuestaria, operativa y de decisión para garantizar dicho derecho, con lo cual se incentiva la accesibilidad, el uso y una mayor garantía del derecho por parte de quienes hacen uso de este.

La exposición se encuentra estructurada de la siguiente forma. Un apartado introductorio, una segunda parte donde se dan precisiones conceptuales en torno a las implicaciones que tiene el derecho de acceso a la información pública, seguido de los antecedentes históricos generales de este derecho y sobre las implicaciones que tiene la información como derecho. Enseguida se realiza una contextualización de los orígenes de la institucionalización del acceso a la información en México, Chile y Colombia.

\footnotetext{
${ }^{3}$ La Ley Modelo de la OEA muestra una visión amplia sobre la forma en que ha evolucionado el paradigma del derecho de acceso a la información en América Latina y fue realizada por un grupo internacional e interdisciplinario de expertos en la materia. En razón de lo anterior, en este trabajo se hace uso de esta ley como un tipo normativo ideal que es empleado, en algunas de sus dimensiones, como marco de comparación con las legislaciones de las unidades de análisis (Chile, Colombia y México).
} 
Posteriormente, se exponen los resultados del análisis comparado de cada una de las legislaciones de los países señalados y el tipo ideal construido con base en la Ley Modelo de la Organización de Estados Americanos (OEA, 2010b). A continuación se plantean algunos datos sobre el uso que se ha hecho de los sistemas de acceso a la información en estos países. Finalmente, se presentan las conclusiones.

\section{Antecedentes históricos del derecho de acceso a la información pública}

Fue en Suecia, en el año de 1766, donde se gestó un primer antecedente histórico del DAIP con la Freedom of Press and the Right of Access to Public Records Act. El segundo país en incorporar en su legislación, aunque de manera implícita más que explícita, el DAIP fue un país latinoamericano, específicamente fue el caso de Colombia, en 1888 (TORRES, 2012). De tal modo, hasta la primera mitad del siglo $\mathrm{XX}$, este derecho sólo se encontraba incorporado en dos países, distantes y distintos en términos de tradición democrática y desarrollo institucional. El tercer país en incorporar este derecho a su legislación fue Finlandia, en 1951. En 1989, sólo 13 países contaban con leyes de acceso a información, sin embargo, para junio de 2013, 94 países $^{4}$.

\section{Principios del derecho de acceso a la información pública}

En 1999, la organización "Artículo 19" publicó un documento titulado El derecho del público a saber, el cual establece una serie de principios mínimos en los que debería basarse la legislación relativa a la libertad de información. De forma más reciente, en agosto de 2008, el Comité Jurídico Interamericano a través de la resolución CJI/RES. 147 (LXXIII-O/08) estableció un listado de diez principios sobre el derecho de acceso a la información. Para los fines de esta investigación se retoman los principios postulados, tanto por Artículo 19 como por la OEA, como parte de los principios normativos que debe contener un régimen de acceso a la información.

Asimismo, se ha optado por centrarse en tres de las características que deben cumplir dichos principios, siendo estos los siguientes: a) máxima divulgación; b) el régimen restringido de excepciones; y c) la existencia de la vía judicial (tener el derecho de recurrir cualquier negativa u obstrucción de acceso a la información ante una instancia administrativa; también debe existir el derecho de apelar las decisiones de este órgano administrativo ante los tribunales de justicia).

\footnotetext{
${ }^{4}$ Véase Open Society Justice Initiative (2013).
} 
El principio de máxima divulgación es el eje que guía la práctica de este derecho, ya que el acceso a la información debe ser garantizado de manera amplia por parte del Estado. El régimen restringido de excepciones está directamente relacionado con el principio de máxima divulgación y también es fundamental, ya que la excepción de acceso a la información debe ser lo menos amplia posible, clara, sin ambigüedades y debidamente justificada. A partir de las excepciones se puede vislumbrar la disposición real por parte del Estado para hacer de la información un bien público y para transparentar su actuación. Finalmente, la existencia de la vía judicial es importante a fin de que los usuarios dispongan de una garantía y tengan la posibilidad de resolver disputas cuando no obtengan una respuesta satisfactoria en torno al ejercicio de este derecho.

\section{Contexto histórico derecho de acceso a la información en los estudios de caso}

Para tener una mejor comprensión de los casos de análisis se considera importante brindar una síntesis del contexto histórico que originó el surgimiento DAIP en Colombia, México y Chile, describiendo el papel que diversos actores tuvieron en impulsar y aprovechar la estructura de oportunidad que permitió poner en la agenda pública el tema.

\section{Contexto del derecho de acceso a la información en Colombia}

En 1984, casi un siglo más tarde a la entrada en vigencia del Código de Organización Política y Municipal (COLOMBIA, 1889), el Ministerio de Gobierno de Colombia propuso un proyecto de ley "por el cual se garantiza el derecho de información" ${ }^{5}$. De dicho proyecto surgió la Ley $57^{6}$, publicada en el Diario Oficial del 12 de julio de 1985, por la cual se ordena la publicidad de los actos y documentos oficiales. Esta ley resultó bastante innovadora para el contexto latinoamericano de su época.

Seis ańos después de la entrada en vigor de la Ley 57, en la nueva Constitución de 1991, se estableció, en el artículo 74ª que "Todas las personas tiene derecho a acceder a los documentos públicos salvo los que establezca la ley”. Hasta principios de 2014, en Colombia no había una ley unificada en acceso a la información, sino un complejo entramado de leyes e instituciones que intervenían en el proceso de solicitud de lo que en ese país se denomina derecho de petición.

\footnotetext{
${ }^{5}$ Colombia (1984).

${ }^{6}$ Ley 57 por la cual se ordena la publicidad de los actos y documentos oficiales (COLOMBIA, 1985).
} 
Pasarían tres décadas (1984-2014), para que se desarrollara una legislación más específica y amplia para garantizar el derecho de acceso a la información. Un proceso que fue fuertemente impulsado desde la sociedad civil, a través de organizaciones como Transparencia por Colombia ${ }^{7}$, el Centro de Estudios de Derecho, Justicia y Sociedad y la Alianza Más Información y Más Derechos, las cuales desde 2009 impulsaron la creación de una "Ley Estatutaria de Acceso a la Información”, tomando como referencia la Ley Modelo de la OEA.

En noviembre de 2011, dicho proyecto fue acumulado con dos proyectos de los Senadores Carlos Emiro Barriga y Juan Manuel Corzo. El resultado fue el texto conciliado al Proyecto de Ley Número 156 de 2011 del Senado, 228 de 2012 Cámara por medio del cual se crea la "Ley de transparencia y del derecho de acceso a la información pública nacional”. Una vez aprobado el proyecto fue enviado, el 21 de junio de 2012, a la Corte Constitucional para su revisión ${ }^{8}$, misma que declaró exequible el proyecto el 10 de mayo de $2013^{9}$, aunque con modificaciones y declarando inexequibles algunos artículos o parte de éstos ${ }^{10}$. Finalmente, el 6 de marzo de 2014, el presidente Juan Manuel Santos la aprobó como la Ley $1712^{11}$.

\section{Contexto del derecho de acceso a la información en Chile}

Desde el inicio de su transición democrática, Chile ha sido destacado como ejemplo de estabilidad política y de crecimiento económico. Sin embargo, los gobiernos de la transición no fueron inmunes a problemas de corrupción, sobre todo los relacionados con empresas públicas como la Empresa Nacional de Petróleo, en 1993, o el caso de la Corporación Nacional del Cobre, en 1994. Ante este escenario de escándalos de corrupción el segundo gobierno de la concertación, encabezado por Eduardo Frei (1994-2000), creó la Comisión Nacional de Ética Pública como medida preventiva a fin de impulsar una agenda y medidas que incentivaran una mayor probidad y transparencia en la gestión pública.

\footnotetext{
7 Transparencia por Colombia (2013a).

${ }^{8}$ Para observar con detalle el proceso legislativo que ha seguido este proyecto de ley véase Congreso Visible.Org (2013).

${ }^{9}$ IFAI (2016).

${ }^{10}$ Para conocer con más detalle los fundamentos de la decisión de la Corte Constitucional y de los artículos exequibles y los inexequibles véanse de las páginas 13 a la 19 del comunicado no 18 de la Corte Constitucional de la República de Colombia (COLOMBIA, 2013).

${ }^{11}$ Ley 1712 por medio de la cual se crea la Ley de Transparencia y del Derecho de Acceso a la Información Pública Nacional (COLOMBIA, 2014).
} 
Pese a este primer esfuerzo preventivo, durante el gobierno de Ricardo Lagos (2000- 2006), se evidenciaron nuevos casos de corrupción como el caso Coimas, el caso Sobresueldos y el caso del Ministerio de Obras públicas, mismos que tuvieron gran impacto en la opinión pública. La primera respuesta del Estado fue que los conflictos se dirimieran en los tribunales, sin embargo, la presión de los medios de comunicación y de algunos líderes de la derecha política incidieron en que en el 2003 se creara la Comisión para el Fortalecimiento de la Transparencia y la Probidad Pública ${ }^{12}$.

En 2005 se introdujo una reforma al artículo $8^{\circ}$ (Ley 20.050) de la Constitución chilena, ampliando el acceso a la información a todos los órganos del Estado. Y se restringieron las causales de reserva de información para proteger el derecho de las personas, el normal funcionamiento del órgano, el interés nacional y la seguridad nacional. En marzo de 2006, Michelle Bachelet asumió, por primera ocasión, la presidencia chilena y durante el primer periodo de su mandato estalla un nuevo caso de corrupción con Chiledeportes. La presidenta respondió mediante la creación de una Comisión encargada de generar una nueva agenda de probidad a fin de "conducente a favorecer la eficiencia, objetividad, responsabilidad pública y calidad profesional de la gestión del Estado" (MUÑOZ, 2008, p. 119). Aún con las reformas legislativas y constitucionales que establecieron que la información de los órganos del Estado era pública, en los hechos su aplicabilidad siguió presentando muchas limitaciones.

Sin embargo, el impuso definitivo llegaría hasta septiembre de 2006, después de que la Corte Interamericana de Derechos Humanos emitiera una resolución contra el Estado Chileno, al considerar que este no estaba cumpliendo con garantizar el derecho a la información del ciudadano Claude Reyes ${ }^{13}$. En dicha resolución la Corte Interamericana seńaló la importancia de adoptar "las medidas necesarias para la creación de prácticas y mecanismos que garanticen a los individuos el acceso efectivo

\footnotetext{
${ }^{12}$ Para mayor detalle al respecto véase Muñoz (2008).

${ }^{13}$ El caso se inició en 1998 y trata sobre la violación del derecho de acceso a la información pública en relación con las consecuencias medioambientales y económicas del fallido proyecto forestal Trillium, también conocido como Río Condor, que iba desarrollándose en el extremo sur de Chile. Los peticionarios había solicitado información al Comité de Inversión Extranjera sobre aspectos comerciales del proyecto. Como sólo recibieron parte de la información solicitada, decidieron recurrir a los tribunales de justicia. Sin embargo, el recurso judicial interpuesto fue rechazado a través de una escueta resolución que se limitaba a decir que adolecía de "manifiesta falta de fundamento". Ante esta respuesta una red de organizaciones chilenas y extranjeras recurrieron a la Corte Interamericana de Derechos Humanos. Véase Muñoz (2008).
} 
a la información pública o a la información de interés colectivo”. A partir de esta coyuntura crítica, producto de la presión internacional, se gestó gradualmente un cambio organizacional mediante el cual Chile dio inicio al proceso de garantía del derecho a la información ${ }^{14}$. La Ley de Acceso a la Información Pública de Chile (Ley 20.285) se publicó en el Diario Oficial el 20 de agosto de 2008, lo cual dio paso a la creación del Consejo para la Transparencia.

\section{Contexto del derecho de acceso a la información en México}

El DAIP en México tuvo su origen en las reformas políticas impulsadas por la Comisión Federal Electoral en 1977, ya que como parte de esta reforma política también se aprobó la modificación del artículo $6^{\circ}$ constitucional, con el cual se establecía, de manera por demás ambigua, que "el derecho a la información seria garantizado por el Estado”. Sin embargo, la ambigüedad de la redacción, la falta de reglamentación de dicha reforma, la opacidad de la estructura institucional y, sobre todo, la ausencia de condiciones democráticas efectivas dieron como resultado que, en los hechos, el ejercicio del derecho fuera improcedente.

Sin embargo, el tema fue impulsado por algunos actores sociales, principalmente periodistas independientes y académicos, quienes abogaron por una mayor regulación y especificidad en torno a cómo podía accederse al uso efectivo del derecho, como una respuesta a las restricciones que el autoritarismo del régimen del Partido Revolucionario Institucional (PRI) hacía en contra de libertades ${ }^{15}$. En las dos décadas siguientes los avances que se dieron fueron escasos, aunque con las interpretaciones de la Suprema Corte de Justicia, tanto las favorables como las no favorables, se pasó gradualmente del reconocimiento del asunto a la adopción del mismo.

\footnotetext{
${ }^{14}$ Dicha legislación tuvo su origen en un proyecto de ley presentado al Congreso por moción de los senadores Hernán Larraín (Unión Demócrata Independiente) y Jaime Gazmuri (Partido Socialista) en enero de 2005, cuando ambos ejercían la presidencia y vicepresidencia del Senado.

${ }^{15}$ Eduardo Guerrero considera que pese a todo, hubo aspectos que permitieron que el tema fuera avanzando gradualmente, así lo explica: Después de 1977 hubo varios intentos para reglamentar el artículo sexto constitucional y, con ello, otorgarle vigencia al derecho a la información. Sin embargo, ninguno fructificó. Aun así, gracias a las presiones de algunas organizaciones de la sociedad civil, a la lógica de la competencia política y cómo sostiene López Ayllon, a la apertura comercial (pues las exigencias entre socios comerciales, de actuar bajo parámetros predecibles y de contar con certeza jurídica para resolver controversias implican, en gran medida, transparencia de regulaciones y procedimientos), los conceptos de transparencia y acceso a la información se abrieron paso poco a poco en la legislación mexicana (2008, p. 58).
} 
Una particularidad del caso mexicano, a diferencia de Colombia y Chile, es que el desarrollo legislativo del DAIP avanzó inicialmente más desde el nivel local, pues en las entidades de Jalisco y Sinaloa se expidieron las primeras leyes de transparencia y acceso a la información pública. Sería hasta el año 2001 - en pleno periodo de alternancia de partido, luego de siete décadas de gobiernos priistas cuando el tema del derecho a la información pública inició su proceso legislativo a nivel federal. El poder Ejecutivo sería quien impulsaría este tema en la agenda pública federal y el 30 de noviembre de 2001, el presidente Vicente Fox presentó ante la Cámara de Diputados una iniciativa que contenía la propuesta de Ley Federal de Transparencia y Acceso a la Información Pública Gubernamental, misma que fue aprobada por unanimidad por el Congreso de la Unión el 24 de abril de 2002. Con esta ley también se creó el Instituto Federal de Acceso a la Información (IFAI), actualmente denominado como Instituto Nacional de Transparencia, Acceso a la Información y Protección de Datos Personales (INAI).

En los años siguientes vendría un efecto cascada que resultó una reforma constitucional (IFAI, 2006) que para 2007 todas las entidades federativas de México contaban con una ley en la materia. Además, en abril de 2007, las Cámaras de Diputados y de Senadores aprobaron por unanimidad la reforma del Artículo 6o, que elevaba el derecho a la información a rango constitucional (LÓPEZ-AYLLÓN y MARVÁN, 2007, p. 20).

A finales del año 2013, el Poder Legislativo se insertó en un nuevo debate y propuestas tendientes a reformar la Constitución y la legislación vigente en materia de acceso a la información, la reforma fue aprobada el 26 de noviembre de 2013. Éstas derivaron en el decreto por el que se reforman y adicionan diversas disposiciones de la constitución en materia de transparencia, mismo que fue promulgado por el presidente Enrique Peńa Nieto, el 7 de febrero de 2014.

\section{Comparativo de las unidades de análisis con la Ley Modelo de la OEA}

La Ley Modelo de la OEA (OEA, 2010a), empleada como tipo ideal para realizar la comparación entre casos, integra las recomendaciones de especialistas en el tema y las experiencias normativas y prácticas que han tenido diversos países de América Latina en materia de derecho a la información, por eso se ha empleado como base para armar la matriz que permitió la comparación entre las legislaciones de Chile, Colombia y México. 
Para estudiar la calidad normativa de las legislaciones de DAIP, en los casos seleccionados, se analizan cinco dimensiones que se consideran sustanciales en un régimen de acceso a la información: 1) características del régimen; 2) los sujetos obligados; 3) el régimen restringido de excepciones; 4) la garantía del régimen de derecho a la información o vía judicial; y 5) comisión de información garante del derecho.

Analizar la calidad normativa de una ley no es tarea sencilla, tal y como se ha señalado en el estudio "Métrica de la Transparencia 2010" (LÓPEZ-AYLLÓN, 2010), pues medir la calidad normativa presenta un doble problema: 1) cómo cuantificar la calidad de una ley; y 2) cuál es el estándar para medirlo.

A partir de la necesidad de poder analizar los estándares mínimos con que cuenta cada una de las unidades de análisis, así como de poder encontrar puntos de convergencia y divergencia entre los tipos de diseño normativo institucional, se optó por crear una matriz de datos consistente en 5 dimensiones, con sus respectivas, subcategorías y variables a fin de poder medir la calidad normativa contrastando las unidades de análisis a partir de la elaboración de un modelo normativo ideal basado en la propuesta de la Ley Modelo de la OEA. A cada dimensión se le asignó una puntuación a partir de tres niveles de importancia (15, 20 y 25), según el peso que se considera tiene dicha dimensión para poder medir cada uno de los casos a partir del modelo ideal basado en una puntuación total de 100. De antemano se reconoce que dicha ponderación no está exenta de sesgos valorativos (los detalles se encuentran disponibles en el anexo metodológico).

\section{Dimensión 1) Características del régimen de acceso a la información}

En la propuesta de operacionalización para el análisis de la primer dimensión denominada "régimen de acceso a la información" (con una valoración total de 15) se incorporaron tres categorías. Esta primera dimensión es fuertemente normativa pues en la valoración se pone énfasis en que el acceso a la información sea considerado a) un derecho humano a nivel constitucional; b) que se incentive la cultura de la transparencia dentro de las organizaciones del Estado de manera activa; y c) que la legislación contenga de manera enunciativa y explícita los principios que, tanto la OEA (OAS, 2008) como la Organización Artículo 19 (1999), han considerado esenciales para un adecuado régimen de acceso a la información.

En el caso de Colombia el acceso a la información pública si está considerado como un derecho humano (Art. 74), lo mismo sucede en el caso de México (Art. 6). Sin embargo, en el caso de Chile, si bien se encuentra incorporado en la constitución (Art. 8), donde se 
establece que "los actos del Estado son públicos", no se señala explícitamente al acceso a la información como un derecho humano.

En lo que se refiere a la transparencia activa, las tres legislaciones incorporan de manera explícita la obligación de que los sujetos obligados publiquen información mínima obligatoria. En cuanto al carácter principista de la legislación para los casos de Chile y Colombia se puede hablar de legislaciones altamente principistas. En contraste, el caso mexicano contiene principios como el de máxima publicidad señalados de manera genérica sin que exista un artículo en que se hagan explícitos dichos principios.

Cuadro 1 - Comparación de los principios del régimen de derecho a la información

\begin{tabular}{|c|c|c|c|c|}
\hline & & & & \\
\hline $\begin{array}{l}\text { 2.- Obligación } \\
\text { de publicar, } \\
\text { 3.- Promoción } \\
\text { de la } \\
\text { transparencia } \\
\text { en la } \\
\text { administración } \\
\text { pública, } \\
\text { 4.- Régimen } \\
\text { restringido de } \\
\text { excepciones, } \\
\text { 5.- } \\
\text { Procedimiento } \\
\text { para facilitar el } \\
\text { acceso, } \\
\text { 6.- Costo, } \\
\text { 7.- Reuniones } \\
\text { abiertas, } \\
\text { 8.- } \\
\text { Precedencia de }\end{array}$ & $\begin{array}{l}\text { 2) El derecho de acceso a } \\
\text { la información se extiende } \\
\text { a todos los órganos } \\
\text { públicos en todos los } \\
\text { niveles de gobierno, } \\
\text { 3) El derecho de acceso a } \\
\text { la información se refiere a } \\
\text { toda información } \\
\text { significante, } \\
\text { 4) Los órganos públicos } \\
\text { deben difundir } \\
\text { información sobre sus } \\
\text { funciones y actividades de } \\
\text { forma rutinaria y } \\
\text { proactiva, } \\
\text { 5) Implementación de } \\
\text { reglas claras, justas, no } \\
\text { discriminatorias y simples } \\
\text { respecto al manejo de } \\
\text { solicitudes de } \\
\text { información, } \\
\text { 6) Las excepciones deben }\end{array}$ & $\begin{array}{l}\text { de máxima } \\
\text { publicidad para } \\
\text { titular universal. } \\
\text { Art. 3.- Otros } \\
\text { principios de la } \\
\text { transparencia y el } \\
\text { acceso a la } \\
\text { información } \\
\text { pública: } \\
\text { a) de } \\
\text { transparencia, } \\
\text { b) de buena fe, } \\
\text { c) de facilitación, } \\
\text { d) de no } \\
\text { discriminación, } \\
\text { e) de gratuidad, } \\
\text { f) de celeridad, } \\
\text { g) de eficacia, } \\
\text { h) de la calidad de } \\
\text { la información, } \\
\text { i) de la } \\
\text { divulgación } \\
\text { proactiva de la }\end{array}$ & $\begin{array}{l}\text { los siguientes } \\
\text { principios: } \\
\text { a) de la } \\
\text { relevancia, } \\
\text { b) de la libertad } \\
\text { de información, } \\
\text { c) de apertura o } \\
\text { transparencia, } \\
\text { d) de máxima } \\
\text { divulgación, } \\
\text { e) de la } \\
\text { divisibilidad, } \\
\text { f) de } \\
\text { facilitación, } \\
\text { g) de la no } \\
\text { discriminación, } \\
\text { h) de la } \\
\text { oportunidad, } \\
\text { i) del control, } \\
\text { j) responsabilidad } \\
\text { y de }\end{array}$ & $\begin{array}{l}\text { interpretación } \\
\text { de esta Ley y } \\
\text { de su } \\
\text { reglamento, } \\
\text { así como las } \\
\text { normas de } \\
\text { carácter } \\
\text { general a las } \\
\text { que se refiere } \\
\text { el artículo 61, } \\
\text { se deberá } \\
\text { favorecer el } \\
\text { principio de } \\
\text { máxima } \\
\text { publicidad y } \\
\text { disponibilidad } \\
\text { de } \\
\text { información } \\
\text { en posesión de } \\
\text { sujetos } \\
\text { obligados. }\end{array}$ \\
\hline
\end{tabular}




\begin{tabular}{|c|c|c|}
\hline $\begin{array}{l}\text { de quienes } \\
\text { revelan } \\
\text { actuaciones } \\
\text { indebidas. }\end{array}$ & $\begin{array}{l}\text { ser establecidas por la ley, } \\
\text { ser claras y limitadas, 7) } \\
\text { La carga de prueba para } \\
\text { justificar cualquier } \\
\text { negativa debe recaer en el } \\
\text { órgano al que le fue } \\
\text { solicitada la información, } \\
\text { 8) Derecho de recurrir } \\
\text { cualquier negativa u } \\
\text { obstrucción de acceso a la } \\
\text { información ante una } \\
\text { instancia administrativa. } \\
\text { También debe existir el } \\
\text { derecho de apelar las } \\
\text { decisiones de este órgano } \\
\text { administrativo ante los } \\
\text { tribunales de justicia, } \\
\text { 9) Sanción para toda } \\
\text { persona que } \\
\text { intencionadamente niegue } \\
\text { u obstruya el acceso a la } \\
\text { información y 10) Deben } \\
\text { adoptarse medidas para } \\
\text { promover, implementar y } \\
\text { asegurar el derecho de } \\
\text { acceso a la información. }\end{array}$ & $\begin{array}{l}\text { información } \\
\text { j) de } \\
\text { responsabilidad } \\
\text { en el uso de la } \\
\text { información. }\end{array}$ \\
\hline
\end{tabular}

Fuente: Elaboración propia.

La mayor puntuación la obtiene la legislación de Colombia con 15 puntos de 15, lo cual evidencia una legislación fuerte en materia normativa. Chile obtiene 10 puntos de 15 porque el acceso a la información no se encuentra incorporado como derecho humano en la Constitución de ese país. Finalmente, México obtiene una puntuación de 10 porque en la legislación no se establecen de manera clara y precisa los principios que conforman el régimen de acceso a la información. 
Tabla 1 - Dimensión 1) Régimen de acceso a la información

\begin{tabular}{|c|c|c|c|c|c|c|c|c|c|c|c|c|c|c|c|}
\hline \multirow[t]{2}{*}{ A) Dimensión } & \multirow[t]{2}{*}{ B) Categoria } & \multirow[t]{2}{*}{ C) Variables } & \multirow{2}{*}{$\begin{array}{l}\text { Criterios de } \\
\text { Evaluación }\end{array}$} & \multicolumn{3}{|c|}{ Ponderación } & \multicolumn{3}{|c|}{ Chile } & \multicolumn{3}{|c|}{ Colombia } & \multicolumn{3}{|c|}{ Mexico } \\
\hline & & & & A & B & C & A & B & C & $\mathbf{A}$ & B & C & $\mathbf{A}$ & B & $\mathrm{C}$ \\
\hline \multirow[t]{3}{*}{$\begin{array}{l}\text { 1) Régimen de Acceso } \\
\text { a la información }\end{array}$} & $\begin{array}{l}1.1 \text { Información } \\
\text { pública como derecho } \\
\text { humano especificado } \\
\text { en la constitución }\end{array}$ & $\begin{array}{l}\text { 1.1.1 Reconocimiento } \\
\text { en la Constitución } \\
\text { como derecho }\end{array}$ & $\begin{array}{l}\text { Que se encuentre } \\
\text { incorporado } \\
\text { (especificado en la } \\
\text { Constitución) }\end{array}$ & \multirow{3}{*}{15} & 5 & 5 & \multirow{3}{*}{10} & 0 & 0 & \multirow{3}{*}{15} & 5 & 5 & \multirow{3}{*}{10} & 5 & 5 \\
\hline & $\begin{array}{l}\text { 1.2 Transparencia } \\
\text { Activa }\end{array}$ & $\begin{array}{l}\text { 1.1.2 Información } \\
\text { mínima olbligatoria } \\
\text { para los sujectos }\end{array}$ & $\begin{array}{c}\text { Que se establezca la } \\
\text { información mínima o } \\
\text { de oficio }\end{array}$ & & 5 & 5 & & 5 & 5 & & 5 & 5 & & 5 & 5 \\
\hline & $\begin{array}{l}\text { 1.3 Legislación } \\
\text { principista del derecho } \\
\text { de acceso a la } \\
\text { información pública }\end{array}$ & $\begin{array}{l}\text { 1.1.3 Principios } \\
\text { Reconocidos }\end{array}$ & $\begin{array}{l}\text { Que se encuentren } \\
\text { incorporados y de } \\
\text { manera explicita los } \\
\text { principios que } \\
\text { conforman el regimen } \\
\text { de derecho a la } \\
\text { información }\end{array}$ & & 5 & 5 & & 5 & 5 & & 5 & 5 & & & \\
\hline
\end{tabular}

Fuente: Elaboración propia.

\section{Dimensión 2) Sujetos obligados en el régimen de acceso a la información}

La segunda dimensión se denomina "sujetos obligados" (con una valoración total de 15) y se encuentra conformada por una categoría y seis variables. En términos generales en los tres casos estudiados se específica con claridad quienes son los sujetos obligados y se tiene una visión amplia sobre éstos, aunque con la Ley 1712 de Colombia y la nueva reforma constitucional en México, Chile ha sido superado en materia de incorporación de sujetos obligados. 
Tabla 2 - Dimensión 2) Sujetos obligados

\begin{tabular}{|c|c|c|c|c|c|c|c|c|c|c|c|c|c|c|c|}
\hline \multirow[t]{2}{*}{ A) Dimensión } & \multirow[t]{2}{*}{ B) Catcgoria } & \multirow[t]{2}{*}{ C) Variables } & \multirow{2}{*}{$\begin{array}{l}\text { Criterios de } \\
\text { Evaluación }\end{array}$} & \multicolumn{3}{|c|}{ Ponderación } & \multicolumn{3}{|c|}{ Chile } & \multicolumn{3}{|c|}{ Colombia } & \multicolumn{3}{|c|}{ Mexico } \\
\hline & & & & $\mathbf{A}$ & B & C & $\mathbf{A}$ & B & $\mathrm{C}$ & $\mathbf{A}$ & B & C & $\mathbf{A}$ & B & C \\
\hline \multirow[t]{6}{*}{ 2) Sujetos Obligados } & \multirow[t]{6}{*}{2.1 Sujetos Obligados } & 2.1.1 Poder Ejecutivo & \multirow{6}{*}{$\begin{array}{l}\text { Que se encuentren } \\
\text { incorporados de } \\
\text { manera expresa en la } \\
\text { ley }\end{array}$} & \multirow{6}{*}{15} & \multirow{6}{*}{15} & 2,5 & \multirow{6}{*}{15} & \multirow{6}{*}{15} & 2,5 & \multirow{6}{*}{15} & \multirow{6}{*}{15} & 2,5 & \multirow{6}{*}{15} & \multirow{6}{*}{15} & 2,5 \\
\hline & & 2.1.2 Poder Legislativo & & & & 2,5 & & & 2,5 & & & 2,5 & & & 2,5 \\
\hline & & \begin{tabular}{|l|} 
2.1.3 Poder Judicial \\
\end{tabular} & & & & 2,5 & & & 2,5 & & & 2,5 & & & 2,5 \\
\hline & & $\begin{array}{l}\text { 2.1.4 Administración } \\
\text { central o federal, } \\
\text { regional, provincial o } \\
\text { municipal. }\end{array}$ & & & & 2,5 & & & 2,5 & & & 2,5 & & & 2,5 \\
\hline & & $\begin{array}{l}2.1 .5 \text { Organos, } \\
\text { organismos o } \\
\text { entidades } \\
\text { independientes o } \\
\text { autónomos de } \\
\text { propiedad del } \\
\text { gobierno o controlados } \\
\text { por el mismo }\end{array}$ & & & & 2,5 & & & 2,5 & & & 2,5 & & & 2,5 \\
\hline & & $\begin{array}{l}2.1 .6 \text { Organizaciones } \\
\text { privadas que reciben } \\
\text { fondos o beneficios } \\
\text { públicos (fideicomisos, } \\
\text { sindicatos, partidos } \\
\text { politicos) } \\
\end{array}$ & & & & 2,5 & & & 2,5 & & & 2,5 & & & 2,5 \\
\hline
\end{tabular}

Fuente: Elaboración propia.

Las tres legislaciones obtuvieron una puntuación de 15 puntos del total de 15 puntos que se podían obtener.

\section{Dimensión 3) Régimen restringido de excepciones de acceso a la información pública}

La tercera dimensión se denomina "régimen restringido de excepciones" (con una valoración total de 25) y se encuentra conformada por cuatro categorías y 14 variables. Las tres legislaciones incorporan la consideración de excepción a la divulgación de información cuando se dañan los intereses privados, por lo que se garantiza el derecho a la privacidad en lo relacionado a la intimidad, la vida, la salud y la seguridad, así como a los intereses legítimos o comerciales en materia económica, industrial y profesional.

La legislación de Chile, México y de Colombia incorporan como parte de la información susceptible de reserva la relacionada con la seguridad pública, la seguridad y la defensa nacional. Sin embargo, Chile va mucho más allá y también incorpora conceptos, un tanto ambiguos, como "orden público"16 e "interés nacional", quizás como reflejo de los vestigios de su añeja doctrina de seguridad nacional y sus históricos conflictos limítrofes con Argentina, Perú y Bolivia.

\footnotetext{
${ }^{16}$ En los comentarios de la Ley Modelo de la OEA se rechaza explícitamente la excepción relativa al "orden público", ya que considera dicha expresión como sumamente vaga por lo que podría es susceptible de ocasiona abusos en su aplicación.
} 
En los tres casos se incorporan como excepción los aspectos relacionados con la conducción de las relaciones internacionales cuando éstas puedan ser en menoscabo del Estado; la prevención, investigación y persecución de delitos e impartición de justicia; los asuntos relacionados con el manejo de la macroeconomía; y la información que contenga las opiniones o recomendaciones del proceso deliberativo de la función pública, hasta que no sea adoptada la decisión para la elaboración o desarrollo efectivo de políticas públicas.

Destaca que en el caso de la legislación mexicana y la ley colombiana se le da relevancia a los derechos humanos, ya que las excepciones de acceso a la información no se aplicarán en casos de violaciones graves a los derechos humanos o delitos de lesa humanidad. Chile no incorpora está referencia específica.

En lo que se refiere a la temporalidad de la reserva, si bien la Ley Modelo establece, en su artículo $42^{\circ}$, lo que denomina como "divulgación histórica", un período de reserva de 12 años que se puede ampliar hasta por otros 12 años, es decir un total de 24 años. Los tiempos de reserva de la información son variables entre los tres casos, el caso mexicano es de 12 ańos ampliable a otros 12, resultando en un total de 24 años, acorde con lo establecido en la Ley Modelo. Por su parte, el caso chileno presenta el más corto con 5 años ampliable a otros 5 , resultando en un total de 10 años. Sin embargo, en el ámbito de la defensa nacional, la planificación militar o estratégica, y de aquéllos cuyo conocimiento o difusión puedan afectar: a) La integridad territorial de Chile; b) La interpretación o el cumplimiento de un tratado internacional suscrito por Chile en materia de límites; c) La defensa internacional de los derechos de Chile; y d) La política exterior del país de manera grave (CHILE, 2008), la excepción podrá ser "indefinida". Finalmente, la ley de Colombia, luego de que la Corte Constitucional declaró inexequible el artículo 22\%, estableció que la temporalidad no podrá extenderse en un periodo mayor a 15 años.

Entre los resultados obtenidos de la ponderación de la dimensión del régimen restringido de excepciones, se tiene que el puntaje más alto del conjunto de las tres categorías analizadas lo obtiene la legislación de Colombia (20.5), seguida por México (17.5) y en último lugar Chile (15.2). Esto podría explicarse porque es la legislación más reciente. 
Tabla 3 - Dimensión 3) Régimen restringido de excepciones

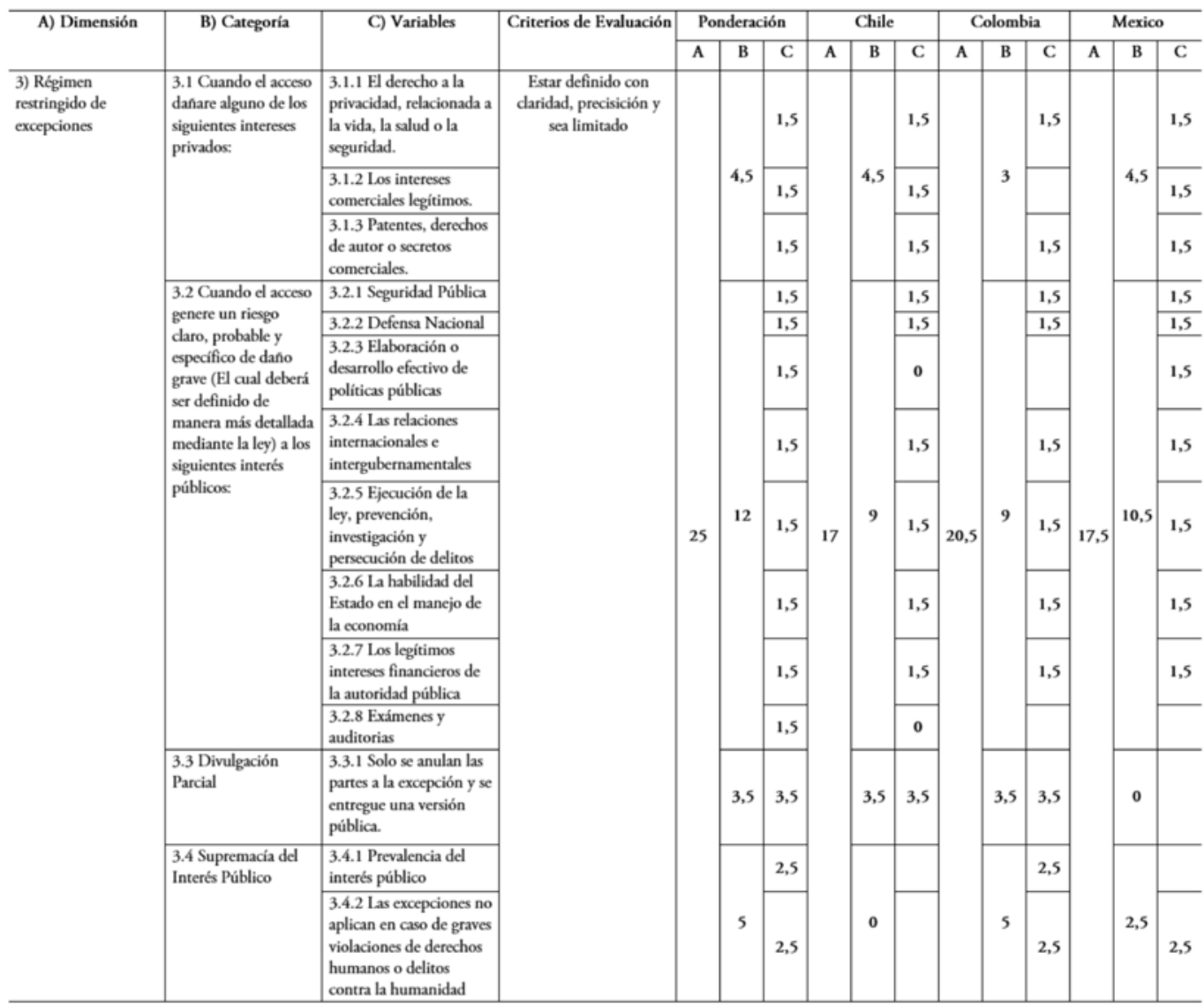

Fuente: Elaboración propia.

\section{Dimensión 4) Garantía del derecho a la información: apelación y via judicial}

La cuarta dimensión se denomina "garantía del derecho a la información: apelaciones" (con una valoración total de 20) y se encuentra conformada por tres categorías y 6 variables. La OEA contempla tres tipos de recursos jurídicos en contra de una negativa de acceso a la información: a) apelación interna (ante el organismo que se solicita la información); b) apelación externa (frente a la comisión de información); y c) revisión Judicial (ante los Tribunales para impugnar una decisión de la Comisión de Información).

En lo que se refiere a la apelación interna, la legislación colombiana contempla (artículo 27) que en caso de que la respuesta a la solicitud de información invoque la reserva de seguridad y defensa o relaciones internacionales, el solicitante 
podrá acudir al recurso de reposición. En el caso de México (artículo 49) se contempla la posibilidad de interponer un recurso de revisión ante la unidad de enlace que haya conocido del asunto, la cual deberá remitir el asunto al IFAI.

La apelación externa (ante la Comisión de Información) se encuentra perfectamente establecida y explicitada en cuanto a la garantía y la forma de ejercerla en las leyes de México y Chile. En la legislación colombiana no se contempla la existencia de la Comisión de Información y en las funciones asignadas al Ministerio Público no se encuentra claramente establecida la de recibir recursos de revisión por parte de los solicitantes.

En cuanto a la tercera categoría, la relativa a la revisión judicial, ésta tiene una gran importancia porque, independientemente de la existencia o no de una Comisión de Información, debe existir la posibilidad de acudir a una instancia judicial que garantice el derecho de acceso a la información pública. La ley de acceso a la información chilena contempla la vía judicial (Artículos 28, 29 y 30) en caso de que las resoluciones del Consejo para la Transparencia no sean aceptadas por el solicitante. En el caso de México las resoluciones del IFAI son vinculatorias, definitivas e inatacables para los sujetos obligados, aunque con la última reforma constitucional (2014) se establece la excepción para el Consejero Jurídico del Gobierno (dependiente del Poder Ejecutivo), quien podrá interponer un recurso de revisión ante la Suprema Corte de Justicia, sólo en el caso de que dichas resoluciones puedan poner en peligro la seguridad nacional conforme a la ley en la materia. Las personas particulares pueden impugnar las resoluciones del IFAI ante el Poder Judicial de la Federación.

En la legislación mexicana, a diferencia de la chilena, no se específica el procedimiento ni los tiempos en caso de impugnar las resoluciones del Instituto ante el Poder Judicial ${ }^{17}$. Por su parte, en el caso de Colombia no se contempla que el Ministerio Público emita resoluciones vinculatorias, definitivas e inatacables para los sujetos obligados. Solamente se establece que el Ministerio Público tiene entre sus atribuciones el realizar informes sobre el cumplimiento de las decisiones de tutelas sobre acceso a la información, así como publicar las decisiones de tutela y normatividad en la materia ${ }^{18}$.

${ }^{17}$ Del 12 de junio de 2003 al 31 de diciembre de 2012 se habían presentado 477 amparos en contra de las resoluciones emitidas por el IFAI (2013, p. 54).

18 En la legislación colombiana actual se contempla que cuando la solicitud de información sea rechazada se ejerza una acción de tutela (similar al amparo en el caso mexicano), a fin de proteger sus derechos fundamentales, la cual se presenta ante los jueces o tribunales con jurisdicción en el lugar 
Tabla 4 - Dimensión 4) Garantía del derecho de información: apelaciones y vía judicial

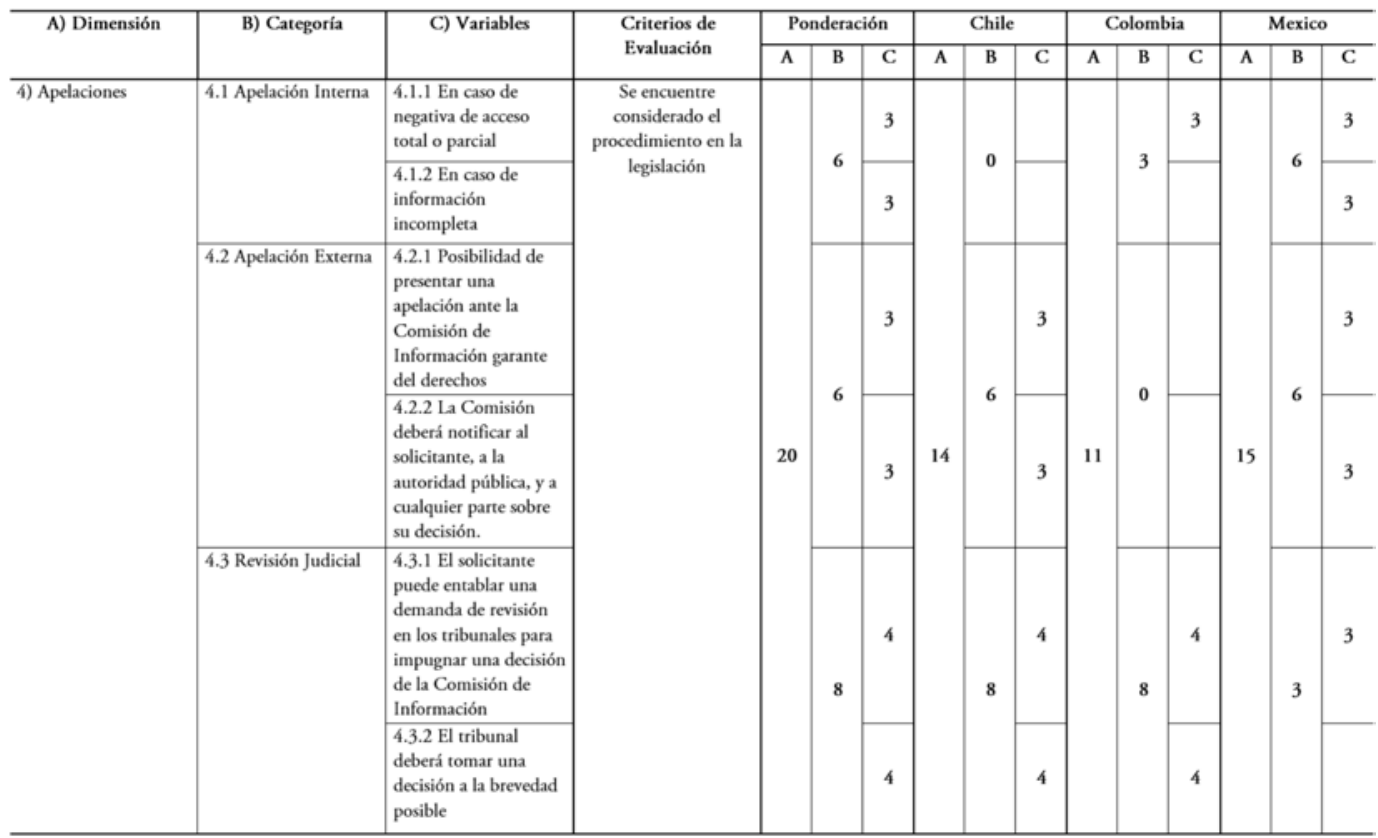

Fuente: Elaboración propia.

En los tres casos, la legislación tiene contemplada la revisión judicial en caso de que una persona considere que su derecho fue vulnerado. En la medición conjunta de las tres categorías de esta dimensión Chile obtuvo 14 puntos, México 13 y Colombia 11, lo cual coloca a la legislación chilena como la más garantista en lo que se refiere a la posibilidad de realizar apelaciones contra decisiones que nieguen o rechacen solicitudes de acceso a la información.

\section{Dimensión 5) Comisión de Información garante del derecho de acceso a la información}

La quinta dimensión se denomina "Comisión de Información garante de derechos" (con una valoración total de 25) y se encuentra conformada por tres categorías y 16 variables. El artículo 53 de la Ley Modelo de la OEA establece la creación de una Comisión de Información encargada de la implementación de la Ley, la cual deberá tener personalidad jurídica completa, con autonomía operativa, de presupuesto y de decisión para cumplir con sus facultades de manera adecuada.

donde ocurre el hecho. La Corte Constitucional ha insistido en la necesidad de aceptar la acción de tutela como mecanismo para reclamar frente a la vulneración del derecho fundamental de petición. 
En esta dimensión 2 de los 3 casos, Chile y México, cumplen con la incorporación de un organismo de control autónomo - con la reciente reforma el IFAI adquiere independencia plena - para garantizar el DAIP y para orientar la política pública respectiva. En el caso de la legislación colombiana la Ley 1712 sobre transparencia y derecho de acceso a la información pública le asigna al Ministerio Público (artículo 23) las funciones relacionadas con las garantías al ejercicio de derecho.

En la medición conjunta de las tres categorías de esta quinta dimensión México obtuvo un total de 23.3 puntos, Chile 22.5 y Colombia 6.5 , lo cual coloca al IFAI (ahora INAI) como la comisión de información más cercana al modelo propuesto por la OEA, aunque el Consejo para la Transparencia de Chile también cumple satisfactoriamente con dicho modelo. El caso colombiano es el más lejano de la recomendación hecha por la OEA, ya que no cuenta con una Comisión de Información autónoma y enfocada específicamente a la promoción y defensa de este derecho. 
Tabla 5 - Dimensión 5) Comisión de Información

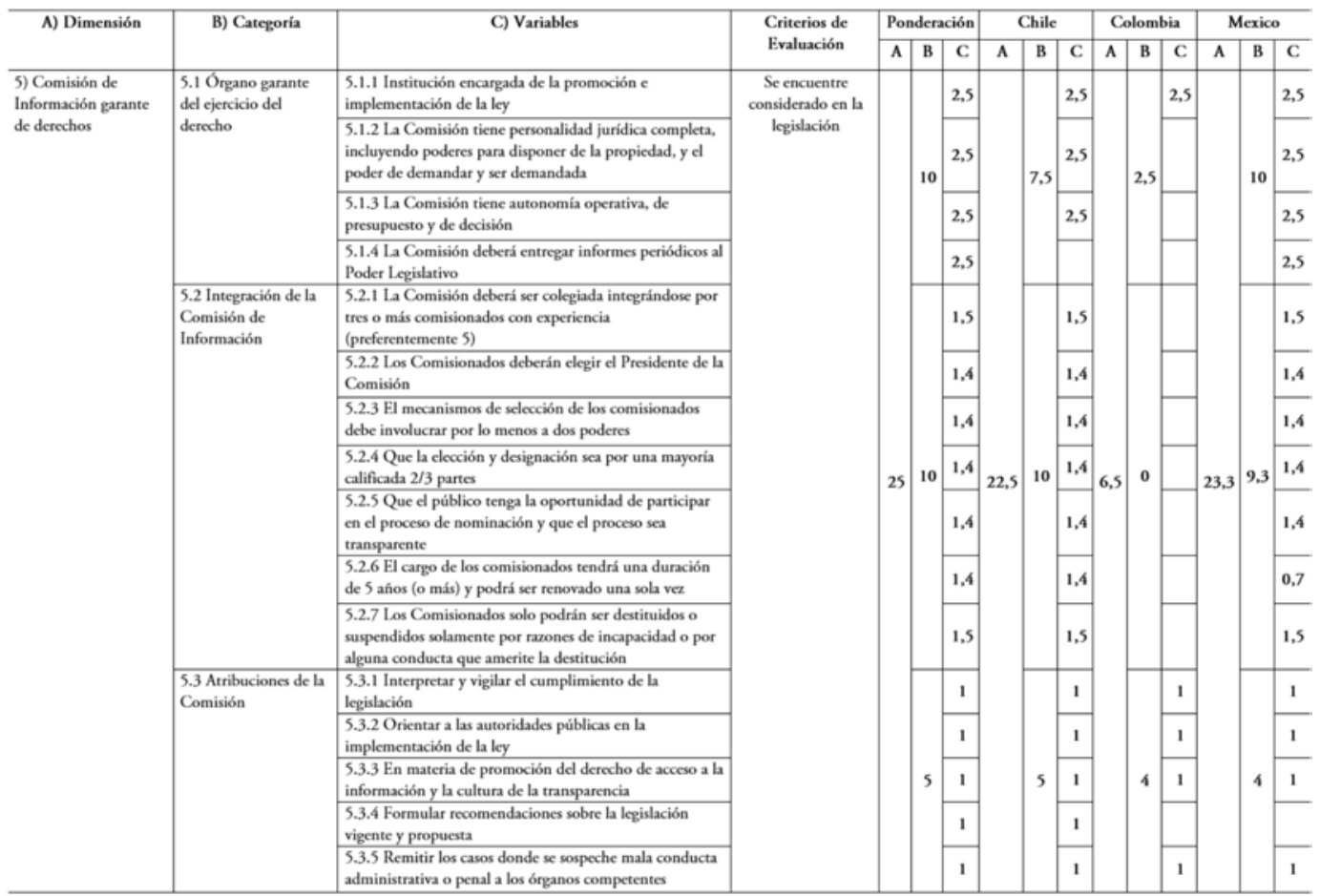

Fuente: Elaboración propia.

En los resultados globales de la comparación realizada los resultados fueron los siguientes: México 78.8/100, Chile 76.7/100 y Colombia 68/100. Por tanto, México tiene el diseńo normativo e institucional más cercano a la Ley Modelo de la OEA. La diferencia entre la legislación mexicana y la chilena es de 2.1 puntos, sin embargo, hay que tomar en cuenta que con la reforma constitucional publicada en febrero de 2014, la legislación mexicana en materia de acceso a la información y transparencia tendrá su tercera reforma desde 2002, mientras que la legislación chilena en vigor no ha sufrido ninguna reforma desde 2008.

\section{Uso del derecho de acceso a la información pública}

\section{Uso del derecho de acceso a la información en México}

Desde la entrada en vigor de la Ley Federal de Transparencia y Acceso a la Información Pública Gubernamental hasta el 31 de diciembre de 2012, la Administración Pública Federal recibió un total de 866, 324 solicitudes de información. De éstas, el $91.4 \%$ habían sido atendidas, $7.2 \%$ se encontraban en 
proceso de atención, y el $1.4 \%$ restante permanecía en espera de que el solicitante precisará la información (IFAI, 2012,).

Gráfico 1 - Número de solicitudes ingresadas a dependencias y entidades de la administración pública federal recibidas entre 2003-2012

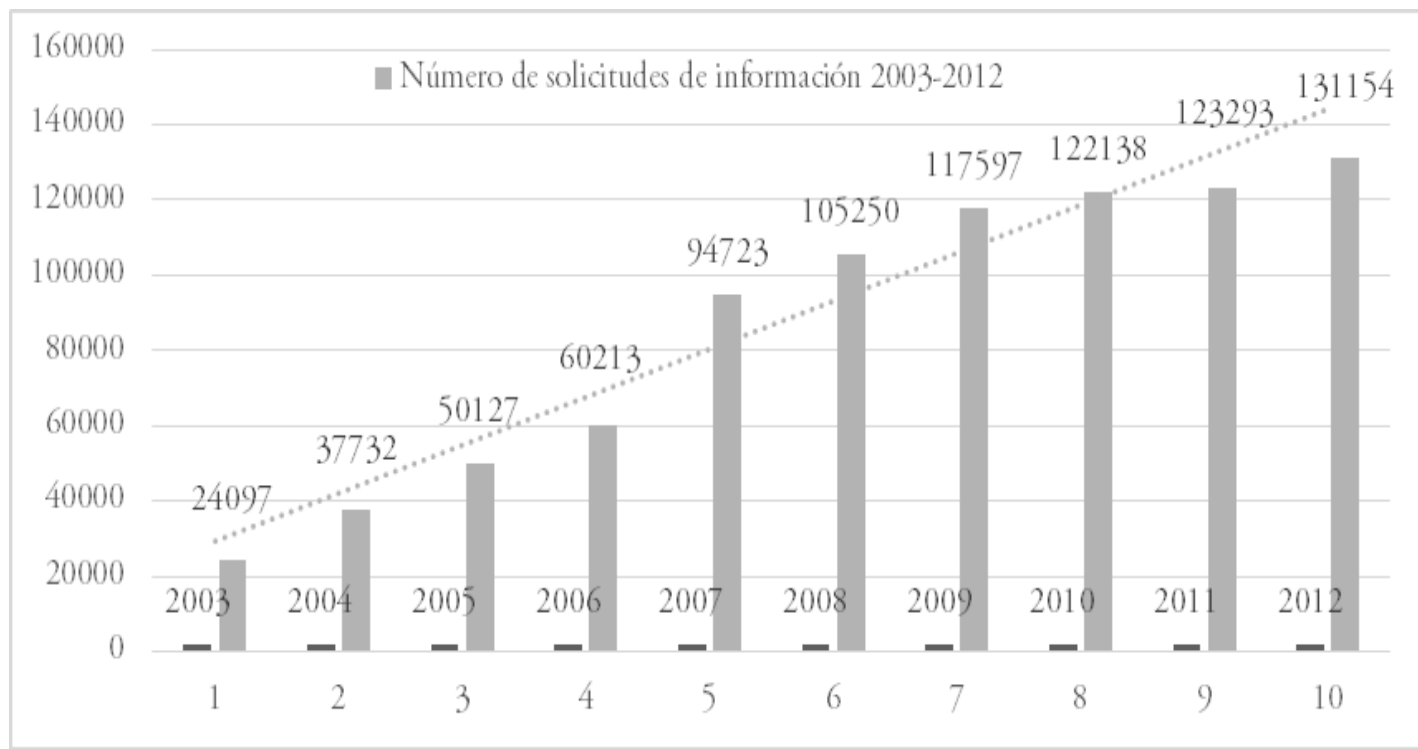

Fuente: Elaboración propia con información de IFAI (2012).

En 2012, el tiempo promedio de respuesta de las solicitudes de información fue de 13.6 días hábiles, promedio por debajo de los 20 días hábiles que establece la ley. En 10 ańos de su operación del IFAI (ahora INAI), comprendida entre junio de 2003 al 31 de diciembre de 2012, ha recibido 45, 657 recursos de revisión ${ }^{19}$. La proporción entre el número total de recursos $(45,657)$ y el número total de solicitudes recibidas por la administración pública federal $(866,324)$ fue de $5.3 \%$

\footnotetext{
${ }^{19}$ El recurso de revisión es uno de los instrumentos centrales para garantizar el derecho de acceso a la información pública. De acuerdo al IFAI se puede definir como: "El medio legal con el que cuentan los particulares para impugnar la respuesta de los sujetos obligados a sus solicitudes de acceso a información pública, ya sea que se les haya negado el acceso a determinada información, la inexistencia de los documentos requeridos o bien, si consideran que la información que se les proporcionó es incompleta o no corresponde a la solicitud que formularon" artículos 49 y 50 de la Ley Federal de Transparencia y Acceso a la Información Pública Gubernamental (LFTAIPG)”.
} 
(IFAI, 2012, p. 46-47). Es decir, solamente el 5.3\% del total de solicitudes han derivado en un recurso de revisión ante el órgano garante.

Gráfico 2 - Número de recursos interpuestos ante el IFAI

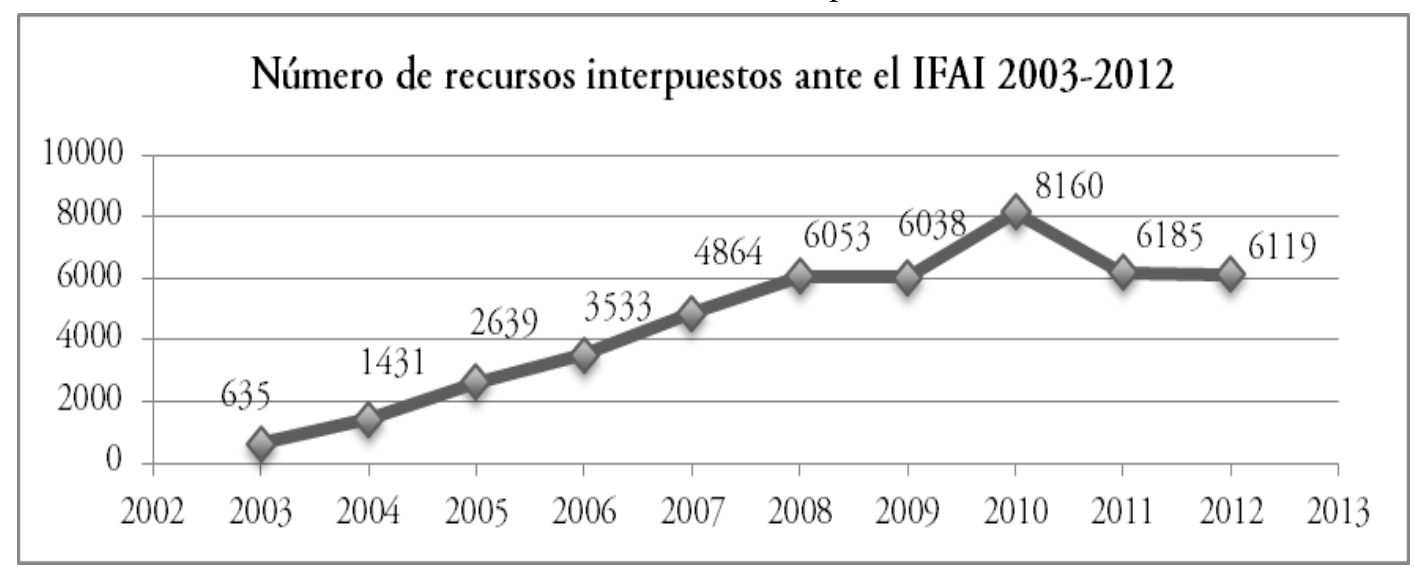

Fuente: Elaboración propia con información de IFAI (2012).

Del 12 de junio de 2003 al 31 de diciembre de 2013, el IFAI resolvió un total de 44,439 recursos (2012, p. 48). Para ese mismo periodo se presentaron 477 amparos en contra de resoluciones emitidas por el IFAI (2012, p. 54), lo cual equivale al $1 \%$ de los recursos resueltos por el IFAI. Esto es significativo porque implica que un porcentaje mínimo (1\%) de los recursos derivan en una revisión judicial.

\section{Uso del derecho de acceso a la información en Chile}

En Chile existen en la práctica dos instituciones estatales con competencia en la implementación del acceso a la información pública: el Consejo para la Transparencia (organismo autónomo) y la Comisión para la Probidad y la Transparencia - ahora se denomina Comisión Defensora Ciudadana y Transparencia y es un organismo dependiente de la presidencia de la República (CAINFO y OPEN SOCIETY FOUNDATIONS, 2011, p. 47-48). En marzo de 2008, mediante el Decreto no 30 del Ministerio Secretaria General de la Presidencia, se creó la Comisión de Probidad y Transparencia ${ }^{20}$, para el apoyo, seguimiento, estudio y análisis de la implementación del acceso a la información en el Poder Ejecutivo.

${ }^{20}$ Desde la promulgación de la ley, en agosto de 2008, la Comisión de Probidad y Transparencia desarrolló un plan de apoyo para que todos los servicios y organismos de Gobierno estuvieran en 
Las solicitudes de acceso a la información pública ingresadas a los servicios y organismos de la Administración Central del Estado Chileno, desde la entrada en vigor de la Ley de Transparencia no 20.285 hasta diciembre de 2012, han sido un total 151,233 solicitudes, presentando un incremento constante.

Gráfico 3 - Número de solicitudes ingresadas a los servicios y organismos de la Administración Central del Estado Chileno recibidas entre 2009 y 2012

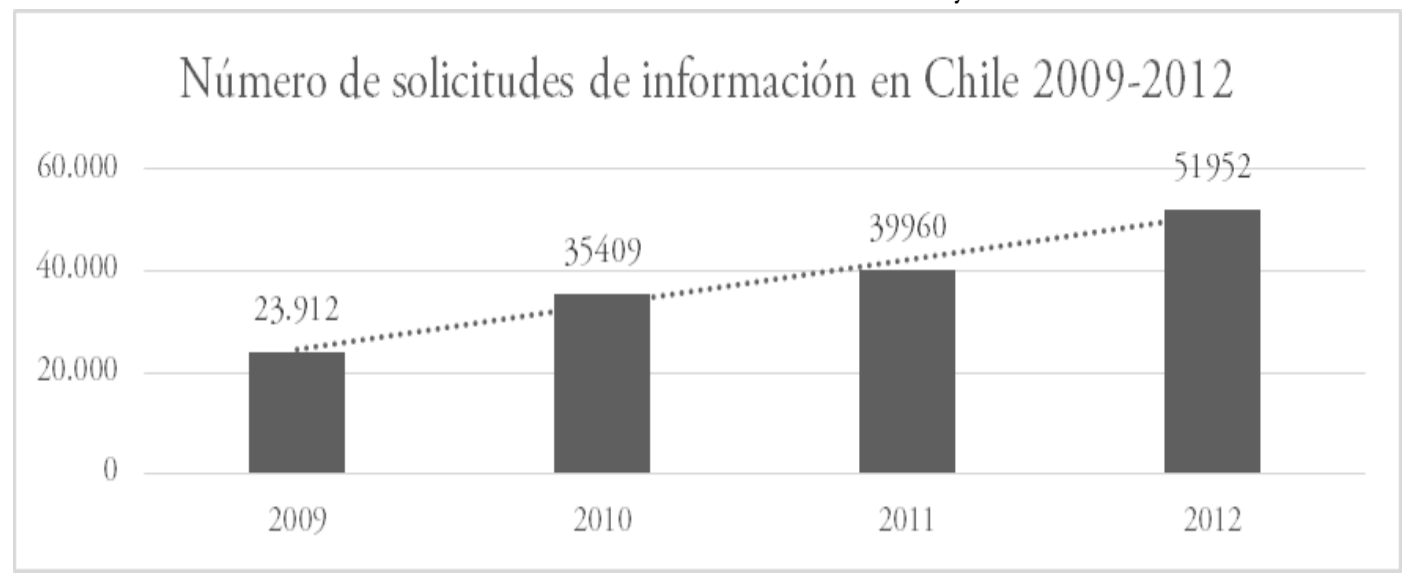

Fuente: Elaboración propia con información de Chile (2009, 2010, 2011 y 2012).

Una de las tareas del Consejo es resolver los amparos por denegación de acceso a la información que le sean formulados de conformidad con la ley, al igual que los reclamos por infracción a los deberes de transparencia activa ${ }^{21}$. Para estos efectos el Consejo funciona en base a dos grandes procesos: el de admisibilidad, que verifica que los reclamos cumplan con los requisitos legales para acogerlos a la

condiciones de implementar la Ley No. 20.285 sin inconvenientes. Con este objetivos se conformó una red de trabajo de representantes ministeriales, que cumplieron el rol de gestores centrales en términos de definir prioridades y líneas de acción generales para el desarrollo del proceso de implementación de la ley por una parte y, por otra, derivar información hacia sus servicios, canalizando la información desde y hacia la Comisión de Probidad y Transparencia (CAINFO y OPEN SOCIETY FOUNDATION, 2011, p. 49).

${ }^{21}$ Se distinguen dos tipos de casos: amparos, que son producto de una disconformidad luego haber realizado una solicitud de información; y reclamos, producto de una disconformidad luego de una revisión de los ítems publicados en la sección "Transparencia Activa". 
tramitación, y los procesos de reclamos, que debe analizar el caso e informarlo al Consejo Directivo $^{22}$.

Desde la creación del Consejo para la Transparencia (abril de 2009) hasta diciembre de 2012 se han recibido 5,040 casos, es decir solo el 3.3\% del total de solicitudes, de los cuales 4,771 son amparos y 269 son reclamos ${ }^{23}$. A su vez, se interpusieron un total de 244 reclamos ante la Corte de Apelaciones en contra de las decisiones del Consejo ${ }^{24}$, lo cual representa el 4.8\% del total. De los 244 reclamos interpuestos en contra del Consejo se han dictado 155 sentencias, lo que equivale al $63.5 \%$.

\section{Uso del derecho de acceso a la información en Colombia}

Acceder a información estadística sobre el ejercicio del derecho de acceso a la información pública en Colombia resultó ampliamente complejo, ya que no hay una única instancia que concentre la estadística sobre los derechos de petición de información que se realizan ante la administración central y departamental. Además en el caso de Colombia coexisten estructuras normativas e institucionales múltiples que enfrentan problemas de coordinación en materia de acceso a la información.

Estas problemáticas se señalan en el "Informe de seguimiento a los compromisos del Gobierno de Colombia en acceso a la información pública", el cual establece que "una de las principales barreras de acceso a la información, se da al complejizar la búsqueda de información e inviabilizar el intercambio eficaz de información entre las mismas entidades públicas" (TRANSPARENCIA POR COLOMBIA, 2013b, p. 13).

A fin de poder tener una idea del uso que las personas hacen del DAIP en Colombia se recurrió a los informes ante el Congreso y los informes anuales de gestión de la Procuraduría General de la Nación entre 2001 y 2013. Sin embargo, dicha información no se encuentra sistematizada por la instancia encargada, en este caso la Procuraduría General de la Nación, a diferencia de lo que sucede con el caso de México y de Chile.

Este es un ejemplo concreto de los beneficios tangibles que presenta la existencia de una Comisión de Información y los problemas que presenta la ausencia de ésta. De hecho, resulta una gran paradoja que la información sobre el acceso, uso y garantía del derecho a la información pública no sea, precisamente eso, pública.

\footnotetext{
${ }^{22}$ Consejo Para La Transparencia (2010).

${ }^{23}$ Consejo Para La Transparencia (2013).

${ }^{24}$ Consejo Para La Transparencia (2013, p. 73).
} 


\section{Reflexiones finales}

Garantizar el DAIP se ha vuelto parte de la "lógica de lo adecuado" en muchos países latinoamericanos - independientemente del tipo de modelo diseñado para hacer vigente este derecho -, como parte de un impulso gestado desde organismos internacionales y desde la propia sociedad civil. Sin embargo, estos esfuerzos coexisten con condiciones institucionales proclives a la cultura de la opacidad, lo cual incide en que este derecho no encuentre un equilibrio adecuado entre la parte normativa y el ejercicio del mismo, corriendo el riesgo de volverse un adorno democrático, en vez de servir como herramienta para la gobernanza democrática.

Pese a estos riesgos, la evidencia encontrada demuestra que en países como México y Chile, donde se ha establecido un marco jurídico de calidad y acorde a los estándares internacionales como los señalados en la Ley Modelo de la OEA, en combinación con una estructura institucional encargada de la promoción, implementación y garantía de este derecho, se ha generado una mayor socialización, institucionalización e incremento en el uso de este derecho por parte de las personas, es decir, pese a las dificultades que se puedan presentar es mejor contar con la legislación y el órgano garante, a fin de modificar gradualmente la lógica burocrática poco proclive a la transparencia.

De tal forma, progresivamente el DAIP y la transparencia gubernamental se han vuelto parte del reportorio de procedimientos que tienen las organizaciones gubernamentales, y aunque aún falta mucho camino por andar para vencer la opacidad y la cultura del secreto, el tener instituciones como el IFAI (INAI) o el Consejo para la Transparencia ha contribuido al cambio institucional mediante el establecimiento de desincentivos para mantener la opacidad. Un ejemplo concreto de estos avances es que hoy, a diferencia de años atrás, se disponen de datos que permiten tener una noción bastante clara de la evolución que ha tenido el uso de este derecho.

Los contextos nacionales en que surgieron las tres legislaciones obedecen a diferentes circunstancias en cuanto a su impulso desde el Estado y la sociedad civil. Un factor común que se puede observar es que, con mayor o menor intensidad, las legislaciones de acceso a la información han sido impulsadas desde la sociedad civil, destacando el caso de México y Colombia, ya que en el caso chileno el impulso obedeció más a la presión de organismos internacionales.

En lo que se refiere a la arquitectura institucional, el modelo chileno tiene una diferencia sustancial con el caso mexicano, ya que el Consejo para la Transparencia 
separa las funciones de fiscalización de las de coordinación de la implementación de la legislación, pues la implementación está a cargo de la Comisión de Probidad (ahora Comisión Defensora Ciudadana Transparencia), la cual depende directamente del Poder Ejecutivo. De tal forma, en el caso chileno coexisten y cooperan entre sí dos organismos, uno autónomo y uno dependiente del Poder Ejecutivo. En el caso mexicano el INAI sólo tenía atribuciones sobre las dependencias o entidades a nivel federal, ya que cada entidad federativa dispone de una legislación propia, sin embargo, con la última reforma el INAI amplía sus facultades a casos que ocurran en las entidades federativas.

México y Chile presentan una buena calidad normativa muy similar entre sí, mientras que Colombia presenta una distancia considerable respecto a Chile y México, resultando, en términos globales, más lejana al tipo ideal de la Ley Modelo de la OEA, pese a ser la legislación más nueva. El diseño institucional mexicano y chileno se presentan como dos de los casos más consolidados en materia de acceso a la información en la región Latinoamericana e incluso frente a otras regiones. Chile, con el Consejo para la Transparencia, evidencia una institución autónoma de control fuerte y estable que opera en un contexto nacional donde los niveles de percepción de la corrupción y los casos públicos de corrupción son menos constantes y notablemente menores en cantidad con respecto al caso mexicano o colombiano. México, con el INAI, también evidencia una institución autónoma y de control fuerte y consolidado, que incluso ha sido paradigma a seguir por otros países. Institucionalidad que se vio reforzada con la reforma al artículo $6^{\circ}$ constitucional en 2006 y con la reforma publicada en febrero de 2014.

En síntesis, México y Chile corroboran la tesis de que en donde se da la conjunción de una buena ley y una Comisión de Información, el ejercicio del derecho y la garantía de este se incrementan notablemente o al menos se hace más accesible y transparente su uso. Caso contrario es el de Colombia, donde, pese a la existencia de una larga tradición jurídica del derecho de petición, el proceso para el uso y la garantía del derecho es mucho menos claro, más complejo y poco transparente.

Finalmente, en un balance general, lo positivo es que el derecho de acceso a la información pública y la transparencia gubernamental continúan expandiéndose y fortaleciéndose en América Latina. A fin de cuentas el acceso a la información es un pilar esencial para impulsar una ciudadanía de mayor intensidad en su involucramiento en la esfera pública y en el control del Estado y sus instituciones, por 
lo que resulta clave para poder mejorar la calidad de la gobernanza democrática que tanta falta hace en nuestra región.

\section{Alfredo Edmundo Fernández de Lara Gaitán é Doutorando em Ciência Política da Universidade dos Andes. E-mail: ae.fernandez10@uniandes.edu.co.}

\section{Bibliografia}

CAINFO; OPEN SOCIETY FOUNDATIONS. Venciendo la cultura del secreto. Obstáculos en la implementación y normas de acceso a la información pública en siete países de América Latina. Montevideo, 2011.2 Disponible en: <http://www.cainfo.org.uy/images/LIBRO\%20\%20Venciendo\%20la\%20Cultura\%20del\%20Secret o.pdf>. Acceso en: 22 sep. 2012.

CHILE. Ley de Transparencia $n^{o}$ 20.285, de 11 de julio de 2008. Sobre Acceso a la Información Pública. Disponible en: <http://www.bcn.cl/ley-transparenciaz. Acceso en: 26 feb. 2012.

CHILE. Reporte anual 2009. Ministerio Secretaría General de la Presidencia, 2009. Diciembre. Disponible en: <http://www.cdc.gob.cl/wpcontent/uploads/documentos/informes_estadisticos/Reporte_anual_2009.pdf $\geq$. Acceso en: 26 nov. 2013.

CHILE. Reporte anual 2010. Ministerio Secretaría General de la Presidencia, 2010. Disponible en: $<$ http://www.cdc.gob.cl/wp-

content/uploads/documentos/informes_estadisticos/Reporte_anual_2010.pdf $\geq$. Acceso en: 26 nov. 2013.

CHILE. Reporte anual 2011. Ministerio Secretaría General de la Presidencia, 2011. Disponible en: $<$ http://www.cdc.gob.cl/wp-

content/uploads/documentos/informes_estadisticos/Reporte_anual_2011.pdf $\geq$. Acceso en: 26 nov. 2013.

CHILE. Reporte anual 2012. Ministerio Secretaría General de la Presidencia, 2012. Disponible en: $<$ http://www.cdc.gob.cl/wpcontent/uploads/documentos/informes_estadisticos/Reporte_anual_2012.pdf $\geq$. Acceso en: 26 nov. 2013.

COLOMBIA. Código Político y Municipal de la República de Colombia. Bogotá: Impr. de "La Luz", 1889.

COLOMBIA. El derecho a la información. Órganos de divulgación, acceso ciudadano a los documentos. Ministerio de Gobierno de la República de Colombia, 1984. 
COLOMBIA. Ley $n^{\circ}$ 57, de 5 de junio de 1985. Por la cual se ordena la publicidad de los actos y documentos oficiales. Disponible en: <http://www.unal.edu.co/secretaria/normas/ex/L0057_85.pdf>. Acceso en: 15 mayo 2013.

COLOMBIA. Comunicado $n^{o}$ 18, 8 y 9 de mayo de 2013. Corte Constitucional, Republica de Colombia. <http:/www.corteconstitucional.gov.co/comunicados/No. $\% 2018 \% 20$ comunicado $\% 2008 \% 20 y \% 2$ 009\%20de\%20mayo\%20de\%202013.pdf>. Acceso en: 21 may. 2013.

COLOMBIA. Ley 1712, de 06 de marzo de 2014. Por medio de la cual se crea la Ley de Transparencia y del Derecho de Acceso a la Información Pública Nacional. Disponible en: <http://wsp.presidencia.gov.co/Normativa/Leyes/Documents/LEY\%201712\%20DEL\%2006\%20D E\%20MARZO\%20DE\%202014.pdf >. Acceso en: 6 mar. 2014.

CONGRESO VISIBLE.ORG. Por medio de la cual se crea la Ley de transparencia y del derecho de acceso a la información pública nacional, y se dictan otras disposiciones. 2013. Disponible en: <http://congresovisible.org/proyectos-de-ley/por-medio-de-la-cual/6501/\#tab=2>. Acceso en: 15 ago. 2013.

CONSEJO PARA LA TRANSPARENCIA. Memoria Institucional 2009. Chile, 210. Disponible en <http:/www.consejotransparencia.cl/consejo/site/artic/20130814/asocfile/20130814160517/memor ia_cplt_2009_web.pdf>. Acceso en: 9 dic. 2013.

CONSEJO PARA LA TRANSPARENCIA. Memoria Institucional 2012. Chile, 2013. Disponible en: <http://www.consejotransparencia.cl/consejo/site/artic/20130814/asocfile/20130814164045/memor ia_compendio_2.pdf>. Acceso en: 9 dic. 2013.

GUERRERO, Eduardo. Para entender la transparencia. México, D.F.: Nostra Ediciones, 2008.

GUILLÁN, Aranzazú. Los órganos garantes de la transparencia y el acceso a la información en Chile y México. Estructura administrativa, gestión interna y funcionamiento del Consejo Para la Transparencia y el Instituto Federal de Acceso a la Información y Protección de Datos. Avances, Oportunidades y Buenas Prácticas. Consejo Para la Transparencia, Chile, 2013. Disponible en: $<$ http://www.consejotransparencia.cl/consejo/site/artic/20130820/asocfile/20130820152206/cplt_if ai_interior.pdf>. Acceso en: 6 dic. 2013.

IFAI. Carpeta de mensajes. Instituto Federal de Acceso a la Información Pública, dez. 2003. Disponible en: <http://inicio.ifai.org.mx/Estudios/estudio06.pdf>. Acceso en: 22 jul. 2012.

IFAI. Décimo Informe de Labores al $\mathrm{H}$. Congreso de la Unión. Instituto Federal de Acceso a la Información Pública, México, D.F., 2012. Disponible en: <http://inicio.ifai.org.mx/_catalogs/masterpage/Informes-2012.aspx>.. Acceso en: 26 oct. 2013.

IFAI. Ley Federal de Transparencia y Acceso a la Información Pública Gubernamental. Instituto Federal de Acceso a la Información y Protección de Datos, México, D.F., 2016. Disponible en: http://www.diputados.gob.mx/LeyesBiblio/ref/lftaipg.htm. Acceso en: 9 dic. 2012.

LÓPEZ-AYLLÓN, Sergio; MARVÁN, María. La transparencia en la República: un recuento de buenas prácticas. México, D.F.: Instituto Federal de Acceso a la Información Pública y Centro de Investigación y Docencia Económicas y IFAI y CIDE., 2007.

LÓPEZ-AYLLÓN, Sergio. El acceso a la información pública como un derecho fundamental: la reforma del artículo $6^{\circ}$ de la Constitución mexicana. Cuadernos de Transparencia. Instituto Federal de Acceso a la Información Pública, n. 17, 2009. 
LÓPEZ-AYLLÓN, Sergio. Métrica de la Transparencia 2010. Centro de Investigación y Docencia Económicas y Conferencia Mexicana de Acceso a la Información Pública, México, D.F. 2010. Disponible en: <http://metricadetransparencia2010.cide.edu/Metrica\%202010.pdf>. Acceso en: 6 dic. 2013.

MENDEL, Toby. El derecho a la información en América Latina. Comparación jurídica. Organización de las Naciones Unidas para la Educación, la Ciencia y la Cultura, Quito, Ecuador, 2009.

MERINO, Mauricio. La transparencia como política pública. En: ACKERMAN, John M. (Coord.). Más allá del acceso a la información. Transparencia, Rendición de Cuentas y Estado de Derecho. México, D.F.: Siglo Veintiuno Editores, 2008.

MUÑOZ, Alex. Transición a la democracia, políticas de probidad y mecanismos internacionales de protección de derechos humanos. El caso de Chile. In: ZALAQUETT José; MUÑOZ, Alex (Eds.). Transparencia y Probidad Pública. Estudios de Caso en América Latina. Santiago: Facultad de Derecho de la Universidad de Chile, 2008. p. 113-129.

OAS. Principios sobre el Derecho de Acceso a la Información. CJI/RES.147 (LXXIII-0/08), 7 de agosto de 2008. Organization Of American States, Río de Janeiro, Brasil. Disponible en: <http://www.oas.org/cji/CJI-RES_147_LXXIII-O-08.pdf>. Acceso en: 10 ago. 2013

OEA. Recomendaciones sobre el Acceso a la Información. Consejo Permanente de la OEA, 21 abr. 2008. Disponible en: <http://www.oas.org/es/sla/ddi/docs/CP-CAJP_2599-08_esp.pdf>. Acceso en: 10 ago. 2013.

OEA. Comentarios y guía de implementación para la ley modelo interamericana sobre acceso a la información. Consejo permanente de la Organización de los Estados Americanos. Comisión de asuntos jurídicos y políticos, 23 abr. 2010a. Disponible en: <http://www.oas.org/dil/esp/CP-CAJP2841-10_esp.pdf>. Acceso en: 10 ago. 2013.

OEA. Ley Modelo de Acceso a la Información Administrativa. 2010b. Disponible en: <http://www.oas.org/juridico/english/ley_modelo_acceso.pdf>. Acceso en: 9 nov. 2012.

OPEN SOCIETY JUSTICE INITIATIVE. Understanding the Tshwane Principles. 12 de junio de 2013. Disponible en: <http://www.opensocietyfoundations.org/briefing-papers/understandingtshwane-principles>. Acceso en: 15 jun. 2013.

ORGANIZACIÓN DE ESTADOS AMERICANOS (OEA). Principios en que debe basarse la legislación relativa a la libertad de información. Junio de 1999. Disponible en: <https:/www.article19.org/data/files/medialibrary/1797/12-04-26-REPORT-rtk-SP.pdf>. Acceso en: 22 oct. 2012.

TORRES, Natalia. Acceso a la Información en Colombia: 124 años después. Freedominfor.org, Washington, 2012. Disponible en: <http://www.freedominfo.org/2012/07/acceso-a-la-informacionen-colombia-124-anos-despues/>. Acceso en: 11 ene. 2013.

TRANSPARENCIA POR COLOMBIA. Preguntas frecuentes: Proyecto de Ley Estatutaria de Acceso a la Información Pública. Transparencia por Colombia, 2013a. Disponible en: <http://www.transparenciacolombia.org.co/index.php?option=com_content\&view=article\&id=164: preguntas-frecuentes-ley-acceso-informacion-publicatransparencia\&catid=87:articulos\&Itemid=448>. Acceso en: 16 ene. 2014.

TRANSPARENCIA POR COLOMBIA. Informe de seguimiento a los compromisos del Gobierno de Colombia en acceso a la información pública. 2013b. Disponible en: $<$ http://www.transparenciacolombia.org.co/index.php?option=com_content\&view=article\&id=317:i 
140 | Alfredo Edmundo Fernández de Lara Gaitán

nforme-de-seguimiento-a-los-compromisos-del-gobierno-de-colombia-en-acceso-a-la-informacionpublica\&catid=117:acceso-a-la-informacion\&Itemid=479>. Acceso en: 16 dic. 2013

VILLANUEVA, Ernesto. Derecho Mexicano de la Información. México: Oxford University Press, 2000.

Texto recebido em 29 de fevereiro de 2016. Aprovado em 16 de março de 2016. 